\title{
The Role of Progesterone Receptors in Breast Cancer
}

\author{
Zhuo Li', Hongrui Wei', Siyan $\mathrm{Li}^{\prime}$, Pei $\mathrm{Wu}^{2}$, Xiaoyun Mao ${ }^{\prime}{ }^{\prime}$ \\ 'Department of Breast Surgery, The First Affiliated Hospital of China Medical University, Shenyang City, Liaoning Province, People's Republic of China; \\ ${ }^{2}$ Department of Surgical Oncology, The First Affiliated Hospital of China Medical University, Shenyang City, Liaoning Province, People's Republic of China
}

Correspondence: Xiaoyun Mao, Department of Breast Surgery, The First Affiliated Hospital of China Medical University, I55 Nanjing North Street, Heping District, Shenyang City, Liaoning Province, I I000I, People's Republic of China, Tel/Fax +86 24 832826I8, Email xymao@cmu.edu.cn

\begin{abstract}
The progesterone receptor (PR) modulates estrogen receptors $\alpha(\mathrm{ER} \alpha)$ action in breast cancer; it is an upregulated target gene of ER, and its expression is dependent on estrogen. PR is also a valuable prognostic biomarker in breast cancer, especially in hormone-positive breast cancer. High expression of PR is more frequently observed in tumors with a better baseline prognosis (ie, luminal A) than tumors with a poor baseline prognosis (ie, luminal B). In the following review, we present the role of PR in breast cancer, including the genomic characteristics and pathways in breast cancer, PR and endocrine therapy.
\end{abstract}

Keywords: progesterone receptor, breast cancer, endocrine therapy

\section{Background}

Steroid hormones and their receptors play multiple roles in the regulation of biological functions, including sex organ development, pregnancy, bone density, cholesterol mobilization, brain function, cardiovascular system, and more. ${ }^{1-5}$ They play an important role in breast cancer development and progression. Almost $70 \%$ of breast cancers are hormone receptor-positive. ${ }^{6}$ Their cells have positive expression of ER and/or PR, which are related to cancer cell growth and spread. Estrogen and its receptor, ER, play a critical role in the development and progression of breast cancer. ${ }^{7}$ PR is an upregulated target gene of ER, its expression is dependent on estrogen, and PR can modulate ER action. ${ }^{8}$ PR is also a valuable prognostic biomarker of overall survival or disease-free survival (DFS) in breast cancer. In this review, we will concentrate on the role of PR in breast cancer subtype, prognosis, treatment and endocrine therapy.

\section{PR Signaling}

Progesterone is a 21-carbon steroid hormone that is involved in the female menstrual cycle, pregnancy and embryogenesis of humans and other species by binding to progesterone receptors. ${ }^{9}$ Studies in a breast mouse model, normal human breast culture, and clinical studies have indicated that estrogen and progesterone are the major proliferative steroid hormones in the mammary epithelium that signal mammary gland development. Estradiol and epithelial ER $\alpha$ signaling are necessary for ductal elongation during early puberty, and progesterone/PR is not necessary for this stage. PR signaling by progesterone is required in the epithelial compartment for ductal elongation and side branching with increased estrogen levels. ${ }^{10-12}$ In early pregnancy, PR signaling can stimulate massive expansion of the epithelial compartment. Progesterone is required for alveolar differentiation in mid- to late pregnancy. At term, progesterone switches to inhibit terminal differentiation and must be removed for lactation. ${ }^{13}$

\section{PR Genomic Characters}

PR is a member of the steroid nuclear receptor family of ligand-dependent transcription factors. PR consists of the central portion of the DNA binding domain (DBD), C-terminal ligand-binding domain (LBD) and amino-terminal domain composed of intrinsically disordered protein. ${ }^{14} \mathrm{PR}$ has two transcriptional activation domains or functions (AFs) that provide interaction 
surfaces for coregulatory proteins: AF1 is located in the N-terminal domain (NTD) and AF2 is located in the LBD. The activated PR recruits diverse functional domains and enzyme activities to the promoter to achieve efficient transcriptional regulation in vivo through interaction with coactivators or corepressors, such as steroid receptor co-activator-1 (SRC-1), SRC2 and SRC-3, cyclic AMP response element-binding protein (CBP/p300) and others. ${ }^{15}$ They will bind the progesterone response element (PRE) of PR and initiate the transcription of target genes. In addition, growth factor-regulated nuclear transcription factors may synergize with agonist-occupied PRs to control the activity of key genes involved in breast cell fate inside the nucleus. ${ }^{16}$ Signal transducer and activator of transcription 1 (STAT1) appears to be directly involved in the step of recognize and destroy developing tumors, ${ }^{17}$ PR can downregulate the STAT1 mediated interferon-alpha signal to escape innate immune surveillance by phosphorylation of STAT $1 .{ }^{18}$ PR exists as two predominant isoforms, PR-A and PR-B, which are transcribed from the same gene located on 11q22-q23 by two distinct promoters and exhibit different transcriptional and biological activities as ligand-activated transcription factors. ${ }^{19,20}$ PR-B is a full-length receptor; PR-A is a truncated form of PR-B lacking 164 amino acids at the $\mathrm{N}$-terminus of the protein. Under progestin-independent condition, PRA is a more active isoform which is compared to PRB, ${ }^{21}$ whereas PR-A is predominantly localized in the nucleus and fails to mediate direct transcriptional events or rapid cytoplasmic changes. ${ }^{22-25}$ Previous research on artificial progesterone-responsive reporter plasmids controlled by the canonical PRE indicated that PR-B is the predominant mediator of progesterone-induced transcriptional activity; however, PR-A has minimal transcriptional activity at the exogenous PRE. ${ }^{26,27}$ PR-A can inhibit the activity of PR-B on ER-chromatin binding activity. ${ }^{8}$ The two isoforms are usually co-expressed at similar levels in normal breast, just at 1:1 ratio. In atypical lesions, there was a significant increase in predominant expression of PRA or PRB, with lesion progression from the normal state to malignancy. ${ }^{28} \mathrm{PR}$ isoform predominance, generally PRA over its counterpart in a high proportion of ductal carcinomas in situ and invasive breast lesions. ${ }^{20,28-31}$ Meanwhile, the ratio of PR-A/PR-B can affect the ability of progesterone to impact gene expression in reproductive tissue and the outcome of breast cancer treatment. ${ }^{30,32-34}$ A serious difference on the viewpoint of PR-A/PR-B in breast cancer prognosis. Some research indicated that high ratio of PRA/PR-B associated with worse prognosis and recurrence after tamoxifen, ${ }^{30}$ yet some research concluded higher PR-A/PR-B related with biomarkers of better prognosis and a luminal A phenotype. ${ }^{34}$ PR-A knock-out mice had uterine and ovarian abnormalities with no effect on the mammary gland with female infertility; while PR-B KO mice had reduced mammary ductal morphogenesis with no effect on the uterus or ovaries. ${ }^{35,36}$ Receptor activator of nuclear factor $\mathrm{\kappa B}(\mathrm{NF}-\mathrm{\kappa B})$ ligand (RANKL) is a paracrine mediator of PR-B during the latter stage of breast development, side branching, and alveologenesis. ${ }^{36}$ Progesterone and PR can induce intrinsic proliferation of PR-negative luminal epithelial cells of the breast by autocrine activation via the RANKL pathway and activation of the downstream target Cyclin D1(CCND1). ${ }^{37}$ Previous studies reported that, compared with progesterone, many natural and synthetic steroid derivatives are nonendogenous ligands and have higher relative binding affinity to progesterone receptors. ${ }^{36-43}$ However, progesterone is the endogenous ligand for PR, but in the references, where there was one-to-one correspondence between hPRs and ligands, and their flexible docking, they found that PR-A or PR-B monomer had higher affinity with estradiol and estrone than progesterone, more particularly to PR-A alone. ${ }^{44}$ The isoform of PR adds the complexity to the study of PR in normal breast and breast cancer.

PR undergoes post-translational modifications, which include acetylation, ubiquitination, methylation, phosphorylation and SUMOylation. ${ }^{45}$ p300 can acetylates Lys-183 of PR for the enhancement of PR-dependent initiation and reinitiation process through accelerated binding of its direct target genes without affecting PR tethering on other transcription factors in response to cellular cues. ${ }^{46,47}$ Additionally, increases of Lys 183 acetylation or inhibition of deacetylation can enhance Ser294 phosphorylation levels and PR activity. Ser294 phosphorylation can also suppress SUMOylation of PR. ${ }^{48}$ Site-specific PR phosphorylation is an important context-dependent mechanism for PR regulation. PR contains more than 10 phosphorylation sites (Ser/Thr) in NTD or hinge region. Mitogen-activated protein kinase (MAPK), cyclin-dependent kinase 2 (CDK2), PKA or CK2 can phosphate PR at specific site. MAPK can phosphate Ser294 and Ser345 of PR. ${ }^{49,50}$ CDK2 phosphates PR Ser190, Ser 294, Ser 554 and Ser 676 to activate PR hormone-dependent transcription. ${ }^{51}$ RANKL pathway related with PR S191 phosphorylation. ${ }^{52,53}$ Malbeteau et al indicated that the type I protein arginine methyltransferase 1 (PRMT1) can methylate PR at the arginine 637 and stables of the receptor, thereby accelerating its recycling and finally its transcriptional activity. ${ }^{54}$ PRMT1 can also methylate ER $\alpha$ at $\operatorname{Arg} 260,{ }^{55}$ it is involved in the ER $\alpha / \mathrm{PR}$ cross talk. PRMT1 is recruited on PR-associated chromatin regions of some progestin-regulated genes. ${ }^{54}$ 


\section{PR Role in Normal Breast}

Estrogen receptor (ER) and PR were positive in approximately $15-30 \%$ of luminal epithelial cells, but not elsewhere in the breast. ${ }^{56}$ Dual-label immunofluorescence techniques indicated that all cells expressing PR also contained ER $\alpha$. In Robert B. Clarke et al study, double labeling using antibodies to ER and then to PgR indicated that $96 \%$ of steroid receptor-positive cells can synthesize both ER and PR. ${ }^{56} \mathrm{PR}$ is an estrogen-regulated gene, and its synthesis in normal and cancer cells requires estrogen and ER. Considerable heterogeneity and cyclical variation exist in nuclear hormone receptor activity among lobules. During the menstrual cycle, peak ER values were observed during the proliferative phase (days 3-8), and the second peak ER was observed in the luteal phase (days 25 and 26). The first PR peak is days 13-14, and the second peak occurred in the luteal phase (days 21-23). ${ }^{57}$ We will discuss their expression in breast cancer in the next section. The menstrual cycling of ER and PR occurs in the normal mammary gland, not in some breast carcinomas. Owing to the specificity of this research, our knowledge of the roles of ER and PR in the breast is derived primarily from a mouse model, offering insight into the biology of human breast development. ER is required at an earlier stage to induce ductal elongation; thus, PR is required for lobuloalveolar development in mice. In the adult mouse mammary gland, PR is expressed in only a fraction of the luminal epithelial cells, while the basal epithelium is PRnegative, and progesterone can act on a subset of mammary epithelial cells to allow for alveolar growth by a paracrine mechanism. ${ }^{10}$ Progesterone upregulates RANKL expression by binding to its receptor in PR-positive breast luminal cells. Then, RANKL binds to RANK expressed on the surface of neighboring PR-negative luminal cells or basal cells, activating downstream pathways of cell proliferation, expansion, and survival. Progesterone can induce adjacent PRpositive cell proliferation by a cell-autonomous, CCND1-dependent mechanism. Progesterone also elicits the proliferation of PR-negative luminal epithelial cells by a paracrine mechanism of the receptor activator nuclear factor- $\mathrm{KB}$ and

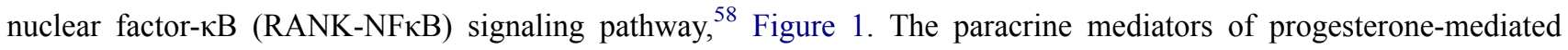
proliferation include Wnt Family Member 4 (Wnt4), RANKL, amphiregulin, calcitonin and the chemokine C-X-C ligand

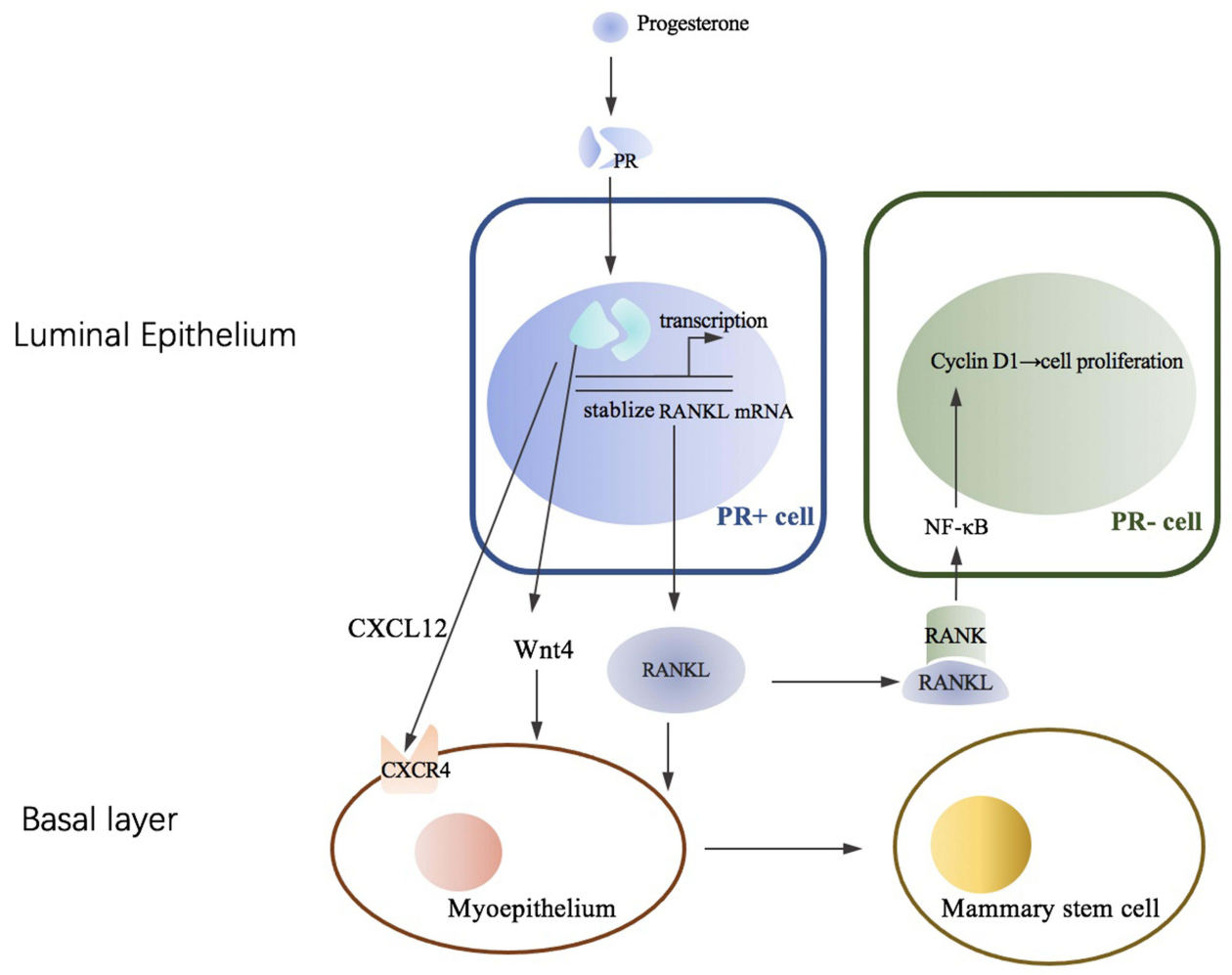

Figure I PR/RANKL signal in human breast. Progesterone can increase RANKL in PR positive luminal breast epithelial cells mainly through inducing the transcription or stabilization of RANKL mRNA. Then the paracrine of RANKL induce the proliferation neighboring PR negative luminal cells by activating NF- $\mathrm{B}$ and cyclin DI pathways. Activated RANKL is also involved in the process of myoepithelium to mammary stem cell and epithelial expansion. PR can mediate CXCLI2-CXCR4 and Wnt Pathway within luminal and basal compartment. 
12 (CXCL12). ${ }^{59}$ PR mediated epithelial-myoepithelial cell interactions by a paracrine mechanism. Progesterone can drive mammary gland development by expansion of the mammary stem cell population, and PR can also regulate this pathway. ${ }^{60}$ Alveolar development during pregnancy is completely absent in the absence of PR.

\section{PR Pathway in Breast Cancer}

A hallmark of precancerous lesions and mammary tumors is an increase in the proportion of proliferating ER/PR-positive cells during breast carcinogenesis ${ }^{61}$ and then a switch from a paracrine to an autocrine mode of regulation by steroid hormones. Cells expressing both ER $\alpha$ and the Ki67 proliferation-associated antigen increased during breast tumorigenesis. Is it the essential step from hyperplasia to ductal carcinoma in situ or invasive breast cancer? Is it the essential process for hormone-negative breast carcinogenesis? Previous research indicated that breast cancer with the harmful breast cancer 1 (BRCA1) variant is more likely to be hormone receptor negative, and BRCA1-driven triple-negative breast cancer has been shown to arise from luminal progenitors. ${ }^{62,63}$ BRCA1 can inhibit PR transcriptional activity by ubiquitination, leading to PR degradation and epigenetic silencing of target promoters. ${ }^{64}$

A previous study indicated that greater exposure to progesterone increases breast cancer risk and leads to the development of hormone receptor-negative tumors in addition to those that are hormone receptor positive. ${ }^{65,66}$ Postmenopausal women with higher circulating progesterone levels experience a $16 \%$ increased risk of breast cancer. ${ }^{67}$ In most target tissues, PR is a direct estrogen-inducing gene, which can synergize with or antagonize ER to affect downstream biological processes. In the promoter interference assays, PR mainly inhibits ER transcription activity through PR-a. ${ }^{68,69}$ In a previous study, progesterone eliminated estrogen-induced tumor growth and was added together with tamoxifen, possibly partly due to the movement of ER from the mitotic site to the apoptosis and cell death genes controlled by PR. ${ }^{8}$ And progesterone may not only directly interfere with ER transcription but also modulate Pol iiimediated transcription and downstream translation to regulate overall tumor growth. ${ }^{70}$ The hormone medroxyprogesterone acetate (MPA) can accelerate the susceptibility of epithelial cells to mammary tumors via the receptor activator of nuclear factor- $\mathrm{kB}$ and its ligand (RANKL/RANK) pathway. Progesterone binds to PR in luminal cells, leading to an increase in RANKL protein mainly through stabilization of its mRNA. Then, RANKL further upregulates its receptor RANK to induce proliferation or differentiation. ${ }^{58}$ The inhibition of RANKL directly resulted in the reduction of tumorigenesis on hormone-induced mammary epithelium at early stages. ${ }^{71}$ Transgenic mice using mouse mammary tumor virus (MMTV)/RANK fusion gene expression showed markedly enhanced susceptibility to mammary tumors compared with wild-type mice. ${ }^{71}$ The MMTV-Cre/rankfloxed/A mouse model, lacking RANK in the mammary epithelia, shows reduced mammary tumorigenesis. The PR-RANK-RANKL pathway is responsible for the major proliferative response of mouse mammary epithelium to progesterone.

\section{PR in Subtype of Breast Cancer}

The seminal work of Perou et al initially identified molecular portraits of breast cancer based upon gene expression profiling of 65 surgical specimens of human breast tissue from 42 individuals using complementary DNA (cDNA) microarrays representing 8102 genes. $^{72}$ Breast cancer subtypes that expressed genes characteristic of luminal epithelial cells, including the ER and PR, and those that were negative for these genes were identified. Luminal-B breast cancer has been defined as ER-positive breast cancer with increased proliferation in many studies. ${ }^{73,74}$ The profiles and algorithm 50 (PAM50) assay provide semiquantitative scoring of the PR protein, but not ER protein, and might help discriminate the genomically defined luminal A from B subtypes. ${ }^{75} \mathrm{PR}$ is an important prognostic marker in breast cancer, and high expression of PR is more frequently observed in tumors with a better baseline prognosis (ie, luminal A) than in tumors with a poor baseline prognosis (ie, luminal B). The study by Rachel Schiff found that ER+/PR- tumors, as defined by gene expression profiles, share gene expression patterns with both ER+/PR+ and ER-/PR-; they bear resemblance to the luminal B subset initially defined by Perou and have poorer prognosis. ${ }^{76}$ The proposed immunohistochemistry (IHC)based definition of luminal A tumors is hydrolysis rates (HR) positive/HER2 negative/Ki-67 less than 14\% and PR more than $20 \%{ }^{77} \mathrm{PR}$ expression cannot predict the benefit of endocrine efficacy in ER-positive breast cancer in clinical trials ${ }^{78}$ possibly because the gene expression profile is not equal to the clinical IHC-based ER/PR status and is closely 
related. There are no data assessing the difference in endocrine efficacy in ER+/PR- breast cancer based on gene signatures or clinical IHC.

\section{PR and Endocrine Therapy}

Breast cancer is heterogeneous and encompasses multiple biologically distinct entities with specific biological behaviors and pathologic features. Breast cancer cells with ER and/or PR depend on estrogen and/or progesterone to grow. ER and/ or PR expression is a crucial determinant for patients to be able to benefit from endocrine therapy targeting estrogen action, such as selective ER modulators (tamoxifen), aromatase inhibitors (letrozole, anastrozole, exemestane), and ER downregulators (fulvestrant). Endocrine therapy is generally well tolerated and an easy-to-administer option for hormone-positive breast cancer patients. This therapy is hampered by a greater treatment expectation and is a major clinical obstacle to the treatment of hormone-positive breast cancer. Adjuvant endocrine therapy can be started either before or after surgery and is usually taken for 5-10 years. The aim of this therapy is to keep cancer from returning. The response to endocrine therapy is confounded in that it may be influenced by the response to the therapy, as well as by the occult advancement of disease and the inherent aggressiveness of the cancer. PR expression is upregulated by ER, and ERpositive/PR-positive breast cancer is common. In a study on SEER data with 666,852 hormone receptor-positive breast cancer, $82.9 \%$ were ER-positive/PR-positive, $15.0 \%$ were ER-positive/PR-negative, and 2.0\% were ER-negative/PRpositive. ${ }^{79}$ It was thought that the absence of PR reflected a nonfunctional ER pathway and was less responsive to selective ER modulators (SERMs), such as tamoxifen. ${ }^{80} \mathrm{~A}$ cohort study indicated that ER-positive/PR-negative breast cancer had worse breast cancer-specific survival than ER-positive/PR-positive subtype breast cancer. ${ }^{79,81}$ This cancer occurs more frequently in elderly, postmenopausal women. ${ }^{82}$ ER-positive/PR-positive breast cancers respond better to SERMs than ER-positive/PR-negative breast cancer ${ }^{81}$ and have better breast cancer-specific survival. ${ }^{79,83,84}$ As assessed by gene expression profiling, ER-positive/PR-negative breast cancer had increased DNA copy number alterations and upregulated PI3K/Akt/mTOR pathway activity. ${ }^{76}$ Phosphatidylinositol-4,5-bisphosphate 3-kinase catalytic subunit alpha (PI3KCA) mutation often correlated with phosphoinositide-3-kinase/protein kinase B/mammalian Target of Rapamycin (PI3K/Akt/mTOR) pathway activation, ${ }^{85}$ and previous research indicated higher PI3KCA mutation in PR-positive tumors than in PR-negative tumors despite ER expression. ${ }^{86,87}$ No research has indicated whether ER-positive/PR-negative breast cancer is related to PI3KCA mutations. In Early Breast Cancer Trialists' Collaborative Group (EBCTCG) overview analysis of a study between 1980 and 1985, PR-positive and PR-negative patients showed similar benefits from tamoxifen (RR 0.81; CI 0.65-1.02 and 0.70; CI 0.49-0.99, respectively) in ER-positive breast cancer patients. ${ }^{88}$

In ER-positive breast cancer, how about PR role in therapy? The retrospective subgroup study on Assay for Transposase-Accessible Chromatin (ATAC) indicated that the time to recurrence was longer for anastrozole- than tamoxifen-treated patients in ER-positive breast cancer, but the differential benefit was greater in the ER-positive/PRnegative subgroup. ${ }^{89}$ PR-negative ER-positive breast cancer has a worse prognosis and is associated with endocrine resistance. PR-negative breast cancer consistently responds less well to endocrine therapy than PR-positive breast cancer, although some of them do benefit. ${ }^{90}$ In the clinic, anti-estrogen therapy alone is avoided for ER-positive/PR-negative breast cancer. Low or absent PR expression may be a predictive benefit of adding chemotherapy in pre- and perimenopausal ER-positive patients. ${ }^{91}$

In clinical work, PR negativity in ER-positive breast cancer is one of the high recurrence risks. How about the potential benefit of escalating endocrine therapy in ER-positive/PR-negative breast cancer? Based on the results from the Suppression of Ovarian Function Trial (SOFT) and Tamoxifen and Exemestane Trial (TEXT), HR-positive/HER2negative premenopausal breast cancer with high recurrence risk may experience $10-15 \%$ absolute improvement in 8 year freedom from distant recurrence with escalating endocrine therapy. ${ }^{92,93}$ In the subgroups of PR expression $20-49 \%$, distant recurrence-free interval (DRFI) favors exemestane plus OFS more than tamoxifen plus OFS, HR $=0.43$. In the PR $<20 \%$ and $>50 \%$ subgroups, DRFI had the same trend, with HRs of 0.59 and 0.75 , respectively. It seems to contradict the previous statement. Despite positive ER, PR loss prompts the development of endocrine resistance. Therefore, escalating endocrine therapy or switching to alternative endocrine agents may overcome endocrine resistance. A pooled analysis indicated that the addition of cyclin-dependent kinase inhibitor (CDKI) to endocrine therapy seemed to benefit all clinicopathological subgroups in hormone receptor-positive, HER2-negative, advanced or metastatic breast cancer, 
regardless of PR expression. ${ }^{94}$ Potential benefits from escalating endocrine therapy in ER-positive/PR-negative breast cancer need to be evaluated by prospective research.

Another unique group is ER-negative/PR-positive breast cancer, and some researchers have considered that it results from inadequate tissue fixation or technical failure of immunohistochemical assays in ER-positive/PR-positive breast cancer. $^{95-97}$ ER-negative/PR-positive breast cancer has decreased with the optimization of immunohistochemical techniques. ${ }^{82,98}$ With the development of molecular biology and immunohistochemistry technology, increasing evidence supports the biological entity of the ER-negative/PR-positive subtype, which represents only a very small proportion of all breast cancers with unique characteristics. ${ }^{99}$ They were found more frequently in younger patients ( $<49$ years), had worse outcomes than ER-positive/PR-positive or ER-positive/PR-negative breast cancer, and probably had a better prognosis than ER-negative/PR-negative breast cancer. ${ }^{84,99}$ The 31\% ER-negative/PR-positive group had Receptor Tyrosine Kinase 2-positive (ERBB2-positive) tumors. There was no difference between ER-negative/PR-positive and ER-negative/PR-negative subtypes with respect to ERBB2 status $(25.3 \%$ vs $29.5 \%){ }^{79}$

\section{Conclusion}

PR is an important steroid hormone receptor in normal mammary gland development, breast carcinogenesis, and advancement. PR is also a biomarker used routinely at diagnosis to characterize breast cancer. PR participated in molecular subtyping and played a determining factor in treatment decisions. However, its complicated roles in different situations need to be elucidated. In the clinic, there is a higher endocrine response in PR-positive breast cancer than in PR-negative breast cancer. It has limited practical utility as a predictive marker for the response to endocrine therapy. However, we still think PR is a very important and interesting marker in breast cancer. PR offers useful clues. How can we make full use of PR? How can we experience and understand the role of PR in practical problems in the clinic? For the treatment of ER-positive/PR-negative or ER-negative/PR-positive breast cancer, escalate or deescalate endocrine therapy? Many questions remain, and more research is needed.

\section{Abbreviations}

PR, Progesterone receptor; Er $\alpha$, Estrogen receptors $\alpha$; DFS, Overall survival or disease-free survival; DBD, DNAbinding domain; LBD, Ligand-binding domain; Afs, Activation domains or functions; NTD, N-terminal domain; SRC-1, Steroid receptor co-activator-1; CBP, Cyclic AMP response element-binding protein; PRE, Progesterone response element; STAT1, Signal transducer and activator of transcription 1; RANKL, Receptor activator of nuclear factor $\kappa B$ ligand; CCND1, Cyclin D1; ER, Estrogen receptor; RANK, Receptor activator of nuclear factor $\kappa B$; RANK-NFkB, Receptor activator nuclear factor- $\mathrm{KB}$ and nuclear factor- $\mathrm{\kappa B}$; Wnt4, Wnt family member 4; CXCL12, C-X-C ligand 12; BRCA1, Breast cancer 1; MPA, Medroxyprogesterone acetate; RANKL/RANK, Receptor activator of nuclear factor- $\mathrm{kB}$ and its ligand; MMTV, Mouse mammary tumor virus; cDNA, Complementary DNA; PAM50, Profiles and algorithm 50; IHC, immunohistochemistry; HR, Hydrolysis rates; SERMs, Selective ER modulators; PI3KCA, Phosphatidylinositol4,5-bisphosphate 3-kinase catalytic subunit alpha; PI3K/Akt/mTOR, Phosphoinositide-3-kinase/protein kinase B/mammalian target of rapamycin; EBCTCG, Early breast cancer trialists collaborative group; ATAC, Assay for transposaseaccessible chromatin; SOFT, Suppression of ovarian function trial; TEXT, Tamoxifen and exemestane trial; DRFI, Distant recurrence-free interval; CDKI, Cyclin-dependent kinase inhibitor; ERBB2, Receptor tyrosine kinase 2.

\section{Author Contributions}

All authors made a significant contribution to the work reported, whether that is in the conception, study design, execution, acquisition of data, analysis and interpretation, or in all these areas; took part in drafting, revising or critically reviewing the article; gave final approval of the version to be published; have agreed on the journal to which the article has been submitted; and agree to be accountable for all aspects of the work.

\section{Funding}

This work was supported by the National Natural Science Foundation of China (No. 81972791). The funders had no role in study design, data collection and analysis, decision to publish, or preparation of the manuscript. 


\section{Disclosure}

The authors declare no conflict of interests.

\section{References}

1. Asavasupreechar T, Saito R, Miki Y, Edwards DP, Boonyaratanakornkit V, Sasano H. Systemic distribution of progesterone receptor subtypes in human tissues. J Steroid Biochem Mol Biol. 2020;199:105599. doi:10.1016/j.jsbmb.2020.105599

2. Hendrix GJ. SIDEBAR: addressing North Carolina Hispanics and Latinos affected by COVID-19: a grassroots approach. $N C$ Med $J$. 2021;82 (1):64-65. doi:10.18043/ncm.82.1.64

3. Mosconi G, Carnevali O, Polzonetti AM. Ovarian development and sex steroid hormones during the reproductive cycle of Podarcis s. sicula Raf. Gynecol Endocrinol. 1991;5(1):7-13. doi:10.3109/09513599109049937

4. Starvaggi Cucuzza L, Divari S, Mulasso C, Biolatti B, Cannizzo FT. Regucalcin expression in bovine tissues and its regulation by sex steroid hormones in accessory sex glands. PLoS One. 2014;9(11):e113950. doi:10.1371/journal.pone.0113950

5. Baños G, Guarner V, Pérez-Torres I. Sex steroid hormones, cardiovascular diseases and the metabolic syndrome. Cardiovasc Hematol Agents Med Chem. 2011;9(3):137-146. doi:10.2174/187152511797037547

6. Clark GM, Osborne CK, McGuire WL. Correlations between estrogen receptor, progesterone receptor, and patient characteristics in human breast cancer. J Clin Oncol. 1984;2(10):1102-1109. doi:10.1200/JCO.1984.2.10.1102

7. Weatherman RV, Fletterick RJ, Scanlan TS. Nuclear-receptor ligands and ligand-binding domains. Annu Rev Biochem. 1999;68:559-581. doi:10.1146/annurev.biochem.68.1.559

8. Mohammed H, Russell IA, Stark R, et al. Progesterone receptor modulates ER $\alpha$ action in breast cancer. Nature. 2015;523(7560):313-317. doi:10.1038/nature 14583

9. Taraborrelli S. Physiology, production and action of progesterone. Acta Obstet Gynecol Scand. 2015;94(Suppl 161):8-16. doi:10.1111/aogs.12771

10. Brisken C, Park S, Vass T, Lydon JP, O’Malley BW, Weinberg RA. A paracrine role for the epithelial progesterone receptor in mammary gland development. Proc Natl Acad Sci U S A. 1998;95(9):5076-5081. doi:10.1073/pnas.95.9.5076

11. Mallepell S, Krust A, Chambon P, Brisken C. Paracrine signaling through the epithelial estrogen receptor alpha is required for proliferation and morphogenesis in the mammary gland. Proc Natl Acad Sci U S A. 2006;103(7):2196-2201. doi:10.1073/pnas.0510974103

12. Lydon JP, DeMayo FJ, Funk CR, et al. Mice lacking progesterone receptor exhibit pleiotropic reproductive abnormalities. Genes Dev. 1995;9 (18):2266-2278. doi:10.1101/gad.9.18.2266

13. Brisken C. Progesterone signalling in breast cancer: a neglected hormone coming into the limelight. Nat Rev Cancer. 2013;13(6):385-396. doi: $10.1038 / \mathrm{nrc} 3518$

14. Gellersen B, Fernandes MS, Brosens JJ. Non-genomic progesterone actions in female reproduction. Hum Reprod Update. 2009;15(1):119-138. doi:10.1093/humupd/dmn044

15. McKenna NJ, Lanz RB, O’Malley BW. Nuclear receptor coregulators: cellular and molecular biology. Endocr Rev. 1999;20(3):321-344. doi:10.1210/edrv.20.3.0366

16. Lange CA, Richer JK, Horwitz KB. Hypothesis: progesterone primes breast cancer cells for cross-talk with proliferative or antiproliferative signals. Mol Endocrinol. 1999;13(6):829-836. doi:10.1210/mend.13.6.0290

17. Khodarev NN, Roizman B, Weichselbaum RR. Molecular pathways: interferon/stat1 pathway: role in the tumor resistance to genotoxic stress and aggressive growth. Clin Cancer Res. 2012;18(11):3015-3021. doi:10.1158/1078-0432.CCR-11-3225

18. Goodman ML, Trinca GM, Walter KR, et al. Progesterone receptor attenuates STAT1-mediated IFN signaling in breast cancer. $J$ Immunol. 2019;202(10):3076-3086. doi:10.4049/jimmunol.1801152

19. Tan H, Yi L, Rote NS, Hurd WW, Mesiano S. Progesterone receptor-A and -B have opposite effects on proinflammatory gene expression in human myometrial cells: implications for progesterone actions in human pregnancy and parturition. $J$ Clin Endocrinol Metab. 2012;97(5):E719-E730. doi:10.1210/jc.2011-3251

20. Graham JD, Yeates C, Balleine RL, et al. Characterization of progesterone receptor A and B expression in human breast cancer. Cancer Res. 1995;55(21):5063-5068.

21. Jacobsen BM, Schittone SA, Richer JK, Horwitz KB. Progesterone-independent effects of human progesterone receptors (PRs) in estrogen receptor-positive breast cancer: PR isoform-specific gene regulation and tumor biology. Mol Endocrinol. 2005;19(3):574-587. doi:10.1210/ me.2004-0287

22. Boonyaratanakornkit V, Bi Y, Rudd M, Edwards DP. The role and mechanism of progesterone receptor activation of extra-nuclear signaling pathways in regulating gene transcription and cell cycle progression. Steroids. 2008;73(9-10):922-928. doi:10.1016/j.steroids.2008.01.010

23. Guiochon-Mantel A, Delabre K, Lescop P, Milgrom E. Nuclear localization signals also mediate the outward movement of proteins from the nucleus. Proc Natl Acad Sci U S A. 1994;91(15):7179-7183. doi:10.1073/pnas.91.15.7179

24. Fu XD, Giretti MS, Baldacci C, et al. Extra-nuclear signaling of progesterone receptor to breast cancer cell movement and invasion through the actin cytoskeleton. PLoS One. 2008;3(7):e2790. doi:10.1371/journal.pone.0002790

25. Migliaccio A, Piccolo D, Castoria G, et al. Activation of the Src/p21ras/Erk pathway by progesterone receptor via cross-talk with estrogen receptor. EMBO J. 1998;17(7):2008-2018. doi:10.1093/emboj/17.7.2008

26. Merlino AA, Welsh TN, Tan H, et al. Nuclear progesterone receptors in the human pregnancy myometrium: evidence that parturition involves functional progesterone withdrawal mediated by increased expression of progesterone receptor-A. J Clin Endocrinol Metab. 2007;92(5):19271933. doi:10.1210/jc.2007-0077

27. Condon JC, Hardy DB, Kovaric K, Mendelson CR. Up-regulation of the progesterone receptor (PR)-C isoform in laboring myometrium by activation of nuclear factor-kappaB may contribute to the onset of labor through inhibition of PR function. Mol Endocrinol. 2006;20(4):764-775. doi:10.1210/me.2005-0242

28. Mote PA, Bartow S, Tran N, Clarke CL. Loss of co-ordinate expression of progesterone receptors A and B is an early event in breast carcinogenesis. Breast Cancer Res Treat. 2002;72(2):163-172. doi:10.1023/A:1014820500738 
29. Recouvreux MS, Diaz Bessone MI, Taruselli A, et al. Alterations in progesterone receptor isoform balance in normal and neoplastic breast cells modulates the stem cell population. Cells. 2020;9(9):2074. doi:10.3390/cells9092074

30. Hopp TA, Weiss HL, Hilsenbeck SG, et al. Breast cancer patients with progesterone receptor PR-A-rich tumors have poorer disease-free survival rates. Clin Cancer Res. 2004;10(8):2751-2760. doi:10.1158/1078-0432.CCR-03-0141

31. Pateetin P, Hutvagner G, Bajan S, Padula MP, McGowan EM, Boonyaratanakornkit V. Triple SILAC identified progestin-independent and dependent PRA and PRB interacting partners in breast cancer. Sci Data. 2021;8(1):100. doi:10.1038/s41597-021-00884-0

32. Cork DM, Lennard TW, Tyson-Capper AJ. Alternative splicing and the progesterone receptor in breast cancer. Breast Cancer Res. $2008 ; 10(3): 207$. doi:10.1186/bcr2097

33. Bonneterre J, Bosq J, Jamme P, et al. Tumour and cellular distribution of activated forms of PR in breast cancers: a novel immunohistochemical analysis of a large clinical cohort. ESMO Open. 2016;1(4):e000072. doi:10.1136/esmoopen-2016-000072

34. Rojas PA, May M, Sequeira GR, et al. Progesterone receptor isoform ratio: a breast cancer prognostic and predictive factor for antiprogestin responsiveness. J Natl Cancer Inst. 2017;109(7). doi:10.1093/jnci/djw317

35. Conneely OM, Mulac-Jericevic B, DeMayo F, Lydon JP, O’Malley BW. Reproductive functions of progesterone receptors. Recent Prog Horm Res. 2002;57:339-355. doi:10.1210/rp.57.1.339

36. Mulac-Jericevic B, Lydon JP, DeMayo FJ, Conneely OM. Defective mammary gland morphogenesis in mice lacking the progesterone receptor B isoform. Proc Natl Acad Sci U S A. 2003;100(17):9744-9749. doi:10.1073/pnas.1732707100

37. Pedroza DA, Subramani R, Lakshmanaswamy R. Classical and non-classical progesterone signaling in breast cancers. Cancers. 2020;12(9):2440. doi:10.3390/cancers 12092440

38. Bain DL, Franden MA, McManaman JL, Takimoto GS, Horwitz KB. The N-terminal region of the human progesterone A-receptor. Structural analysis and the influence of the DNA binding domain. J Biol Chem. 2000;275(10):7313-7320. doi:10.1074/jbc.275.10.7313

39. Bain DL, Franden MA, McManaman JL, Takimoto GS, Horwitz KB. The N-terminal region of human progesterone B-receptors: biophysical and biochemical comparison to A-receptors. J Biol Chem. 2001;276(26):23825-23831. doi:10.1074/jbc.M102611200

40. Tetel MJ, Giangrande PH, Leonhardt SA, McDonnell DP, Edwards DP. Hormone-dependent interaction between the amino- and carboxyl-terminal domains of progesterone receptor in vitro and in vivo. Mol Endocrinol. 1999;13(6):910-924. doi:10.1210/mend.13.6.0300

41. Giangrande PH, Kimbrel EA, Edwards DP, McDonnell DP. The opposing transcriptional activities of the two isoforms of the human progesterone receptor are due to differential cofactor binding. Mol Cell Biol. 2000;20(9):3102-3115. doi:10.1128/MCB.20.9.3102-3115.2000

42. Heneghan AF, Connaghan-Jones KD, Miura MT, Bain DL. Coactivator assembly at the promoter: efficient recruitment of SRC2 is coupled to cooperative DNA binding by the progesterone receptor. Biochemistry. 2007;46(39):11023-11032. doi:10.1021/bi700850v

43. Molenda-Figueira HA, Murphy SD, Shea KL, et al. Steroid receptor coactivator-1 from brain physically interacts differentially with steroid receptor subtypes. Endocrinology. 2008;149(10):5272-5279. doi:10.1210/en.2008-0048

44. Hasan TN, Masoodi TA, Shafi G, Alshatwi AA, Sivashanmugham P. Affinity of estrogens for human progesterone receptor A and B monomers and risk of breast cancer: a comparative molecular modeling study. Adv Appl Bioinform Chem. 2011;4:29-36. doi:10.2147/AABC.S17371

45. Ilicic M, Zakar T, Paul JW. Epigenetic regulation of progesterone receptors and the onset of labour. Reprod Fertil Dev. 2019;31(6):1035-1048. doi:10.1071/RD18392

46. Liu Z, Wong J, Tsai SY, Tsai MJ, O’Malley BW. Sequential recruitment of steroid receptor coactivator-1 (SRC-1) and p300 enhances progesterone receptor-dependent initiation and reinitiation of transcription from chromatin. Proc Natl Acad Sci U S A. 2001;98(22):12426-12431. doi:10.1073/ pnas. 231474798

47. Chung H, Sze S, Tay A, Lin VJ. Acetylation at lysine 183 of progesterone receptor by p300 accelerates DNA binding kinetics and transactivation of direct target genes. J Biol Chem. 2014;289(4):2180-2194. doi:10.1074/jbc.M113.517896

48. Knutson T, Daniel A, Fan D, et al. Phosphorylated and sumoylation-deficient progesterone receptors drive proliferative gene signatures during breast cancer progression. Breast Cancer Res. 2012;14(3):R95. doi:10.1186/bcr3211

49. Faivre E, Daniel A, Hillard C, Lange C. Progesterone receptor rapid signaling mediates serine 345 phosphorylation and tethering to specificity protein 1 transcription factors. Mol Endocrinol. 2008;22(4):823-837. doi:10.1210/me.2007-0437

50. Qiu M, Olsen A, Faivre E, Horwitz K, Lange C. Mitogen-activated protein kinase regulates nuclear association of human progesterone receptors. Mol Endocrinol. 2003;17(4):628-642. doi:10.1210/me.2002-0378

51. Hagan C, Daniel A, Dressing G, Lange CA. Role of phosphorylation in progesterone receptor signaling and specificity. Mol Cell Endocrinol. 2012;357:43-49. doi:10.1016/j.mce.2011.09.017

52. Perumbilavil S, Piccardi A, Buchnev O, Kauranen M, Strangi G, Assanto G. All-optical guided-wave random laser in nematic liquid crystals. Optics Express. 2017;25(5):4672-4679. doi:10.1364/OE.25.004672

53. Grimm S, Ward R, Obr A, et al. A role for site-specific phosphorylation of mouse progesterone receptor at serine 191 in vivo. Mol Endocrinol. 2014;28(12):2025-2037. doi:10.1210/me.2014-1206

54. Malbeteau L, Poulard C, Languilaire C, et al. PRMT1 is critical for the transcriptional activity and the stability of the progesterone receptor. iScience. 2020;23(6):101236. doi:10.1016/j.isci.2020.101236

55. Poulard C, Treilleux I, Lavergne E, et al. Activation of rapid oestrogen signalling in aggressive human breast cancers. EMBO Mol Med. 2012;4 (11):1200-1213. doi:10.1002/emmm.201201615

56. Clarke RB, Howell A, Potten CS, Anderson E. Dissociation between steroid receptor expression and cell proliferation in the human breast. Cancer Res. 1997;57(22):4987-4991.

57. Silva JS, Georgiade GS, Dilley WG, McCarty KS Sr, Wells SA Jr, McCarty KS Jr. Menstrual cycle-dependent variations of breast cyst fluid proteins and sex steroid receptors in the normal human breast. Cancer. 1983;51(7):1297-1302. doi:10.1002/1097-0142(19830401)51:7<1297::AIDCNCR2820510720>3.0.CO;2-Z

58. Beleut M, Rajaram RD, Caikovski M, et al. Two distinct mechanisms underlie progesterone-induced proliferation in the mammary gland. Proc Natl Acad Sci U S A. 2010;107(7):2989-2994. doi:10.1073/pnas.0915148107

59. Cenciarini ME, Proietti CJ. Molecular mechanisms underlying progesterone receptor action in breast cancer: insights into cell proliferation and stem cell regulation. Steroids. 2019;152:108503. doi:10.1016/j.steroids.2019.108503

60. Alferez DG, Simões BM, Howell SJ, Clarke RB. The role of steroid hormones in breast and effects on cancer stem cells. Curr Stem Cell Rep. 2018;4(1):81-94. doi:10.1007/s40778-018-0114-Z 
61. Khan SA, Rogers MA, Obando JA, Tamsen A. Estrogen receptor expression of benign breast epithelium and its association with breast cancer. Cancer Res. 1994;54(4):993-997.

62. Bach K, Pensa S, Zarocsinceva M, et al. Time-resolved single-cell analysis of Brcal associated mammary tumourigenesis reveals aberrant differentiation of luminal progenitors. Nat Commun. 2021;12(1):1502. doi:10.1038/s41467-021-21783-3

63. Lim E, Vaillant F, Wu D, et al. Aberrant luminal progenitors as the candidate target population for basal tumor development in BRCA1 mutation carriers. Nat Med. 2009;15(8):907-913. doi:10.1038/nm.2000

64. Calvo V, Beato M. BRCA1 counteracts progesterone action by ubiquitination leading to progesterone receptor degradation and epigenetic silencing of target promoters. Cancer Res. 2011;71(9):3422-3431. doi:10.1158/0008-5472.CAN-10-3670

65. Chlebowski RT, Rohan TE, Manson JE, et al. Breast cancer after use of estrogen plus progestin and estrogen alone: analyses of data from 2 women's health initiative randomized clinical trials. JAMA Oncol. 2015;1(3):296-305. doi:10.1001/jamaoncol.2015.0494

66. Fournier A, Fabre A, Mesrine S, Boutron-Ruault MC, Berrino F, Clavel-Chapelon F. Use of different postmenopausal hormone therapies and risk of histology- and hormone receptor-defined invasive breast cancer. J Clin Oncol. 2008;26(8):1260-1268. doi:10.1200/JCO.2007.13.4338

67. Trabert B, Bauer DC, Buist DSM, et al. Association of circulating progesterone with breast cancer risk among postmenopausal women. JAMA Network Open. 2020;3(4):e203645. doi:10.1001/jamanetworkopen.2020.3645

68. Wen DX, Xu Y-F, Mais DE, Goldman ME, McDonnell DP. The A and B isoforms of the human progesterone receptor operate through distinct signaling pathways within target cells. Mol Cell Biol. 1994;14(12):8356-8364. doi:10.1128/mcb.14.12.8356-8364.1994

69. Zheng Z-Y, Bay B-H, Aw S-E, Lin VC. A novel antiestrogenic mechanism in progesterone receptor-transfected breast cancer cells. J Biol Chem. 2005;280(17):17480-17487. doi:10.1074/jbc.M501261200

70. Finlay-Schultz J, Gillen AE, Brechbuhl HM, et al. Breast cancer suppression by progesterone receptors is mediated by their modulation of estrogen receptors and RNA polymerase III. Cancer Res. 2017;77(18):4934-4946. doi:10.1158/0008-5472.CAN-16-3541

71. Gonzalez-Suarez E, Jacob AP, Jones J, et al. RANK ligand mediates progestin-induced mammary epithelial proliferation and carcinogenesis. Nature. 2010;468(7320):103-107. doi:10.1038/nature09495

72. Perou CM, Sørlie T, Eisen MB, et al. Molecular portraits of human breast tumours. Nature. 2000;406(6797):747-752. doi:10.1038/35021093

73. Tran B, Bedard PL. Luminal-B breast cancer and novel therapeutic targets. Breast Cancer Res. 2011;13(6):221. doi:10.1186/bcr2904

74. Wirapati P, Sotiriou C, Kunkel S, et al. Meta-analysis of gene expression profiles in breast cancer: toward a unified understanding of breast cancer subtyping and prognosis signatures. Breast Cancer Res. 2008;10(4):R65. doi:10.1186/bcr2124

75. Parker JS, Mullins M, Cheang MC, et al. Supervised risk predictor of breast cancer based on intrinsic subtypes. J Clin Oncol. 2009;27(8):11601167. doi:10.1200/JCO.2008.18.1370

76. Creighton CJ, Kent Osborne C, van de Vijver MJ, et al. Molecular profiles of progesterone receptor loss in human breast tumors. Breast Cancer Res Treat. 2009;114(2):287-299. doi:10.1007/s10549-008-0017-2

77. Prat A, Cheang MC, Martín M, et al. Prognostic significance of progesterone receptor-positive tumor cells within immunohistochemically defined luminal A breast cancer. J Clin Oncol. 2013;31(2):203-209. doi:10.1200/JCO.2012.43.4134

78. Selli C, Dixon JM, Sims AH. Accurate prediction of response to endocrine therapy in breast cancer patients: current and future biomarkers. Breast Cancer Res. 2016;18(1):118. doi:10.1186/s13058-016-0779-0

79. Li Y, Yang D, Yin X, et al. Clinicopathological characteristics and breast cancer-specific survival of patients with single hormone receptor-positive breast cancer. JAMA Network Open. 2020;3(1):e1918160. doi:10.1001/jamanetworkopen.2019.18160

80. Cui X, Schiff R, Arpino G, Osborne CK, Lee AV. Biology of progesterone receptor loss in breast cancer and its implications for endocrine therapy. $J$ Clin Oncol. 2005;23(30):7721-7735. doi:10.1200/JCO.2005.09.004

81. Arpino G, Weiss H, Lee AV, et al. Estrogen receptor-positive, progesterone receptor-negative breast cancer: association with growth factor receptor expression and tamoxifen resistance. J Natl Cancer Inst. 2005;97(17):1254-1261. doi:10.1093/jnci/dji249

82. Rakha EA, El-Sayed ME, Green AR, et al. Biologic and clinical characteristics of breast cancer with single hormone receptor positive phenotype. $J$ Clin Oncol. 2007;25(30):4772-4778. doi:10.1200/JCO.2007.12.2747

83. Blows FM, Driver KE, Schmidt MK, et al. Subtyping of breast cancer by immunohistochemistry to investigate a relationship between subtype and short and long term survival: a collaborative analysis of data for 10,159 cases from 12 studies. PLoS Med. 2010;7(5):e1000279. doi:10.1371/ journal.pmed.1000279

84. Bardou VJ, Arpino G, Elledge RM, Osborne CK, Clark GM. Progesterone receptor status significantly improves outcome prediction over estrogen receptor status alone for adjuvant endocrine therapy in two large breast cancer databases. J Clin Oncol. 2003;21(10):1973-1979. doi:10.1200/ JCO.2003.09.099

85. Janku F, Wheler JJ, Westin SN, et al. PI3K/AKT/mTOR inhibitors in patients with breast and gynecologic malignancies harboring PIK3CA mutations. J Clin Oncol. 2012;30(8):777-782. doi:10.1200/JCO.2011.36.1196

86. Maruyama N, Miyoshi Y, Taguchi T, Tamaki Y, Monden M, Noguchi S. Clinicopathologic analysis of breast cancers with PIK3CA mutations in Japanese women. Clin Cancer Res. 2007;13(2 Pt 1):408-414. doi:10.1158/1078-0432.CCR-06-0267

87. Cizkova M, Susini A, Vacher S, et al. PIK3CA mutation impact on survival in breast cancer patients and in ER $\alpha$, PR and ERBB2-based subgroups. Breast Cancer Res. 2012;14(1):R28. doi:10.1186/bcr3113

88. Dowsett M, Houghton J, Iden C, et al. Benefit from adjuvant tamoxifen therapy in primary breast cancer patients according oestrogen receptor, progesterone receptor, EGF receptor and HER2 status. Ann Oncol. 2006;17(5):818-826. doi:10.1093/annonc/mdl016

89. Dowsett M, Cuzick J, Wale C, Howell T, Houghton J, Baum M. Retrospective analysis of time to recurrence in the ATAC trial according to hormone receptor status: an hypothesis-generating study. J Clin Oncol. 2005;23(30):7512-7517. doi:10.1200/JCO.2005.01.4829

90. Osborne CK, Schiff R, Arpino G, Lee AS, Hilsenbeck VG. Endocrine responsiveness: understanding how progesterone receptor can be used to select endocrine therapy. Breast. 2005;14(6):458-465. doi:10.1016/j.breast.2005.08.024

91. Lin WB, Chovelon JM, Jaffrezic-Renault N. Fiber-optic surface-plasmon resonance for the determination of thickness and optical constants of thin metal films. Appl Opt. 2000;39(19):3261-3265. doi:10.1364/AO.39.003261

92. Pagani O, Francis PA, Fleming GF, et al. Absolute improvements in freedom from distant recurrence to tailor adjuvant endocrine therapies for premenopausal women: results from TEXT and SOFT. J Clin Oncol. 2020;38(12):1293-1303. doi:10.1200/JCO.18.01967

93. Francis PA, Pagani O, Fleming GF, et al. Tailoring adjuvant endocrine therapy for premenopausal breast cancer. $N$ Engl $J$ Med. 2018;379(2):122137. doi:10.1056/NEJMoa1803164 
94. Gao JJ, Cheng J, Bloomquist E, et al. CDK4/6 inhibitor treatment for patients with hormone receptor-positive, HER2-negative, advanced or metastatic breast cancer: a US Food and Drug Administration pooled analysis. Lancet Oncol. 2020;21(2):250-260. doi:10.1016/S1470-2045(19) 30804-6

95. De Maeyer L, Van Limbergen E, De Nys K, et al. Does estrogen receptor negative/progesterone receptor positive breast carcinoma exist? J Clin Oncol. 2008;26(2):335-6; author reply 6-8.

96. Kornaga EN, Klimowicz AC, Guggisberg N, et al. Evaluation of three commercial progesterone receptor assays in a single tamoxifen-treated breast cancer cohort. Mod Pathol. 2016;29(12):1492-1500. doi:10.1038/modpathol.2016.151

97. Nadji M, Gomez-Fernandez C, Ganjei-Azar P, Morales AR. Immunohistochemistry of estrogen and progesterone receptors reconsidered: experience with 5993 breast cancers. Am J Clin Pathol. 2005;123(1):21-27.

98. Kornaga EN, Klimowicz AC, Guggisberg N, et al. A systematic comparison of three commercial estrogen receptor assays in a single clinical outcome breast cancer cohort. Mod Pathol. 2016;29(8):799-809. doi:10.1038/modpathol.2016.74

99. Rhodes A, Jasani B. The oestrogen receptor-negative/progesterone receptor-positive breast tumour: a biological entity or a technical artefact? J Clin Pathol. 2009;62(1):95-96. doi:10.1136/jcp.2008.060723

\section{Publish your work in this journal}

Drug Design, Development and Therapy is an international, peer-reviewed open-access journal that spans the spectrum of drug design and development through to clinical applications. Clinical outcomes, patient safety, and programs for the development and effective, safe, and sustained use of medicines are a feature of the journal, which has also been accepted for indexing on PubMed Central. The manuscript management system is completely online and includes a very quick and fair peer-review system, which is all easy to use. Visit http://www.dovepress.com/testimonials.php to read real quotes from published authors.

Submit your manuscript here: https://www.dovepress.com/drug-design-development-and-therapy-journal 